\title{
Characterization and reactivity of geogenic manganese-oxides from South Africa
}

\author{
M.H.H. FiSCHEL ${ }^{1 *}$, C.E. CLARKE ${ }^{2}$, AND D.L. SPARKS \\ ${ }^{1}$ University of Delaware, Newark, DE 19716, USA, \\ (*correspondence: fischel@udel.edu, dlsparks@udel.edu) \\ ${ }^{2}$ Stellenbosch University, Stellenbosch 7599, South Africa, \\ (cdowding@sun.ac.za)
}

This study characterizes the physical and chemical properties and the reaction kinetics of the geogenic manganese oxides found in Graskop, South Africa. Despite their importance in cycling redox-sensitive compounds in natural systems, much remains unknown about the oxidative capacity of natural manganese-oxides under environmental conditions. To study how these manganese-oxides react, soils were collected from Graskop, South Africa. Soils were excavated with a range of manganese concentrations up to $200 \mathrm{~g} / \mathrm{kg}$. The soil in each horizon was analyzed to determine the chemical and physical properties of the soils, including cation exchange capacity (CEC) and point of zero charge (PZC). A sequential extraction was used to determine the chemical form of the manganese and iron in this soil. X-ray powder diffraction (XRD) and scanning electron microscopy (SEM) were used to characterize the mineralogy of the crystalline material found in the clay fraction. A series of batch reactions were used to determine the capacity of these soils to oxidize arsenite into arsenate. Reactions were conducted under varied $\mathrm{pH}$ and temperature to elucidate how these conditions influenced the oxidation reaction. Samples were analyzed by liquid chromatography-inductively coupled plasma-mass spectrometry (LC-ICP-MS). Solid samples were analyzed at NSLS-II on beamline 4-BM (XFM) and micro-XRD was used to determine the mineralogy of the manganese nodules and soil matrix on the micro-scale. This study provides key insights to more fully understand the role of manganese-oxides in controlling redox-sensitive reactions in the environment. 